\title{
Problems and Countermeasure about Basic Japanese Teaching Practice
}

\author{
Li Dai \\ School of Foreign Languages, Yan'an University, Yan'an 716000, China \\ daili600@126.com
}

\begin{abstract}
Basic Japanese is an important foundation course for junior students in Japanese major. Especially Basic Japanese for freshman of Japanese affects their Japanese professional ability throughout the university period. In the process of Japanese teaching for the Japanese students, I noticed the problems and put forward some countermeasures.
\end{abstract}

Keywords: Basic Japanese; Existing problems; Countermeasure.

\section{Introduction}

"Basic Japanese" is a core course for junior students in Japanese major. It is designed to improve students' basic skills of listening, speaking, reading and writing. Cultivate the students' language ability and cultural accomplishment, laying a solid foundation for senior Japanese. "Basic Japanese (1)" and "Basic Japanese (2)" make the freshman as the object of teaching. Normally zero-based students is from the Japanese pronunciation, vocabulary, syntax and so on. Therefore, "Basic Japanese" for junior students in Japanese major is not only the students' professional class, but also the learning effect is related to the students the language knowledge level.

\section{Existing problems}

In the process of daily Japanese teaching for the Japanese students, I noticed some problems. These problems are not only existing problems of students, but also the existing problems in teaching mode. The following, is the detailed analysis on these problems.

\subsection{Students lack the correct cognition and positioning about Japanese major}

Many students chose Japanese professional just because interested in Japanese pop culture or animation, and game. They think that Japanese learning just like pay attention to these popular elements which are easy and funny. Some students think that there are a lot of Chinese characters in Japanese, maybe it is not difficult as other foreign languages. However, they find that really start to learn, Japanese language learning is a long and arduous process, the difficulty is more than the imagination, then they even lost the initial enthusiasm.

Zero level of the Japanese study determine that during the learning process students should be required the steadfast efforts, they should not be lax, especially in the freshman year at the beginning stage. This is far from the idea that means "enter university learning should be a very easy process," besides the inadaptability in new surroundings. It is easy to make some students lose the direction, even began to confusion, leading to weariness.

\subsection{Students lack learning enthusiasm and positive autonomy}

It is called that "No man is his craft's master the first day." Autonomy learning emphasized at the university life, ask the students to master the habit of independent learning. The freshman has just experienced the university entrance exam, to enter university, no longer have a large number of review tasks and the examination paper of exams followed behind, so some students lose the motivation. There are some students are professional swap by learning the Japanese professional, they are not interested in it. The students of the post-90s, are thinking active, but sometimes seem to be lack of resilience, in the process of learning, when facing the difficulties and errors, they retreat easily. These are all lead to the students lacking of enthusiasm and initiative in Japanese studying.

\subsection{Teaching method is relatively single, still continuing the traditional teaching methods}

The current teaching method is still in the traditional teaching way, meaning: the teacher speaks, students listen. For the zero-based freshman, of course should continue the way of teachers in 
teaching. This way is short of a few new, making students lack some of the interest in learning. So, as a teacher, should insist on the original teaching methods while trying to increase some new teaching link.

\section{Countermeasures to the problems}

I put forward the following countermeasures to solve above problems.

\subsection{Pay attention to the first Japanese lesson}

The first Japanese lesson relates students and teacher, so it is very important. Students' previous knowledge of Japanese and acquaintance of Japanese curriculum, speculation, and even doubts will be verified or answered in the first class. So, teachers should pay more attention to the first Japanese lesson. In the first Japanese lesson, teacher should explain major aims, learning objectives of Japanese to the students, let the students have a more clear and objective understanding and the line of thinking.

\section{2 play well the teacher's guidance}

Freshman just entered university is both novel and confusion to the unknown college life, they don't know where to start. To this, teachers should play the guiding role. Whether the pronunciation stage, or the basic Japanese stage, Kana's pronunciation, mastering of the words, learning of important sentence pattern, teachers in the process should play a good role of supervision and inspection. For example, remedy the wrong pronunciation, give the dictation of learned words regularly, and check the conversation reciting in textbooks and so on. Urge the students to master good knowledge in various ways, and gradually make the students form the habit of language learning.

\subsection{Arouse the students' interest in learning Japanese}

In the basis of daily Japanese teaching, teacher must consciously let the students timely to experience the joy of success from the induction phase, in order to cultivate students' interest in learning Japanese and build up their confidence, stimulate students' enthusiasm for learning Japanese, arouse the enthusiasm of students' learning, to form a good learning habit and atmosphere. The students will benefit in the whole learning stage.

For example, in the process of the class, teachers can according to the characteristics of the students, set some specific link, make the students participate in, to improve the students' interest. In the studying of this sentence" te ku da sai", teachers can prepare some sentences about this sentence patterns, ask the class to stand up. Students listen to the teacher read the sentence. They who hear instruction first and make the right moves, can sit. By analogy, the last student can show programs about Japanese as a small punishment. Another example, when learning the causal relationship sentences " $\sim \mathrm{ka}$ ra, $\sim$ ", teacher prepares a number of causality sentences before the class, and writes the cause and result clauses on the note, disrupts the order, then lets the students taking it randomly. After the students get the note, they should look for the other half of the sentence to match their sentence in the shortest possible time. So, it achieves the lively activities. Teacher can also according to the development practice of the textbook, require students separated as several groups to use the sentence patterns, making the scene dialogue, let the students to remember the language knowledge in the performance easily.

This way could improve the ability of students to participate in, make them realize learning achievements and fun in learning, help them improve the interest in learning Japanese.

\subsection{Cultivate students' independent-study ability}

Language learning is a long and hard process, students need to continue to adhere to and need the steadfast efforts. Learning in university emphasizes studying by selves, students in the process of learning should master the methods of self-study and improve the self-learning ability. The teacher can guide at beginning, students are required to form a series of basic study habits, such as preview before class, review after class, discover questions and solve questions in time. Then, morning reading, reciting, listening comprehension, conversation, etc are also the necessary learning ways of self-study. Also, teacher should guide the student to read extracurricular books related to the Japanese, 
and so on, to help students improve the ability of autonomous learning through a period of time's requirements and guidance, .

\subsection{Add new link in the traditional teaching way, making full use of all kinds of teaching resources}

In the process of teaching, teachers also need to keep advancing with the Times, try to add new link in the traditional teaching way, in order to increase the effectiveness of classroom teaching. Interact with students timely or take a few time to let students as host also can be regarded as an effective way of teaching. Such as: speech on duty. After the first semester, students will be able to use what they have learned to make the simple expression. According to the order of student number, students do the daily speech for 3 5 minutes every day. Therefore, five minutes before class everyday become students' own time. Students can show their own speech bearing, interact with other students and so on. It is a good opportunity of communication between students.

Make full use of all kinds of teaching resources. Teacher can make full use of multimedia in the teaching process, playing the text recording to the students, displaying related images, especially when explaining words, teacher can use the multimedia display to make the student obtaining more intuitive understanding. For example, in the interpretation of the words like "kabuki", "kimono", the image material can make the student obtain the most intuitional cognition. In addition, the teacher also can choose a few of simple Japanese voice data, small video or simple Japanese songs, as supplementary information to share with students, which broaden students' vision, improve students' interest in learning.

Introduce some of the more commonly used Japanese learning website or television to students. For example: The HuJiang website, The Asahi Shimbun website, People's Daily net in Japanese, and so on. Although it is difficult for the freshman, insist for a long time, it is useful to the cultivation of language sense, it also can help learning new words, grammar, and cultural knowledge and so on.

\subsection{Import the Japanese culture in the Basic Japanese course}

Language is the carrier of culture, leaving the existence of culture, language is thin. In the process of the words and the text interpretation, if only explaining the words and grammar is boring. So, though still in the primary stage, teacher can still import Japanese culture in the process of interpretation of the words and the text. For example, when learning the word "hatsu moude", teacher can explain the cultural meaning of this word. When learning the lesson named "ru-ru to ma na-", teacher should explain the simple Japanese etiquette culture to the students, placing the language on the cultural level, so it can make students grasp the deep meaning of the language better.

\section{Summary}

For the problems in Basic Japanese, I put forward the corresponding countermeasures. The process of language learning needs effort. In this process, teachers should play the guiding role. Under the teacher's guidance, students should give play to subjective activity, cultivate the ability of self-study, cultivate good study habits, solid the base of basic Japanese learning, and then lay a more solid foundation for the following Japanese learning.

\section{Acknowledgments}

This work was financially supported by Educational Commission of Shanxi Province (15JK1807).

\section{References}

[1] Fan Wu. Primary comprehensive teaching problems and countermeasures research in Japanese [J]. Examination of weekly magazine, Vol.10 (2016) No.19, p.88.

[2] Ting Wu, Lizhen Tuo. Discuss of Japanese teaching mode [J]. Education for Chinese After-school, Vol.10 (2014) No.15, P.184-185. 
[3] Yanhui Xiao. Introduction to basic Japanese course teaching skills [J]. Journal of Jiamusi Vocational Institute, Vol.30 (2013) No.6, P.418-419.

[4] Shi Ying. Introduction to the problems existing in the Japanese teaching practice [J]. Journal of Brand Research, Vol.28 (2015) No.1, p.247. 